\title{
Manganese dioxide nanosheet-decorated ionic liquid-functionalized graphene for electrochemical theophylline biosensing
}

\author{
Xuming Zhuang ${ }^{\mathrm{a}}$, Dandan Chen ${ }^{\mathrm{a}}$, Shengnan Wang ${ }^{\mathrm{a}}$, Huitao Liu ${ }^{\mathrm{a}, *}$, Lingxin Chen ${ }^{\mathrm{a}, \mathrm{b}, *}$ \\ a College of Chemistry and Chemical Engineering, Yantai University, China \\ ${ }^{\mathrm{b}}$ Key Laboratory of Coastal Environmental Processes and Ecological Remediation, Yantai Institute of Coastal Zone Research, Chinese Academy of Sciences, \\ China
}

\section{A R T I C L E I N F O}

\section{Article history:}

Received 6 April 2017

Accepted 11 May 2017

Available online 12 May 2017

\section{Keywords:}

$\mathrm{MnO}_{2}$ nanosheets

Ionic liquid

Graphene

Theophylline

Electrochemical sensor

\begin{abstract}
A B S T R A C T
In this study, a novel theophylline (TP) sensor based on $\mathrm{MnO}_{2}$ nanosheets/ionic liquid-functionalized graphene $\left(\mathrm{MnO}_{2}\right.$ nanosheets/IL-graphene) was fabricated. Cyclic voltammetry (CV) was used to evaluate the electrochemical behavior of the modified electrode. The surface concentration of the electroactive species, $\Gamma$, was calculated to be approximately $2.316 \times 10^{-10} \mathrm{~mol} \mathrm{~cm}^{-2}$ for $\mathrm{MnO}_{2}$ nanosheets on the modified electrode. The resulting system was suitable for electrochemical sensing because of the combined advantages of $\mathrm{MnO}_{2}$ nanosheets and IL-graphene. The differential pulse voltammetric (DPV) results indicated a high ability of the $\mathrm{MnO}_{2}$ nanosheets/IL-graphene/GCE to catalyze the oxidation of TP and, hence, to detect it. DPV determination of TP gave linear responses over the concentration range from 1 to $220 \mu \mathrm{M}$, and the detection resolution limit was $0.1 \mu \mathrm{M}$. Furthermore, the applicability of the $\mathrm{MnO}_{2}$ nanosheets/IL-graphene/GCE for analysis in real samples was successfully demonstrated.
\end{abstract}

(C) 2017 Elsevier B.V. All rights reserved.

\section{Introduction}

Theophylline (TP) is a compound mainly used to treat emphysema, bronchial asthma, cardiac difficulty breathing and bronchitis [1]. Pharmacological action of TP is related to its serum concentrations [2], and the range in which the chemical is effective and safe. Moreover, when taken orally, its absorption is poor because of various factors in the body and multiple differences between individuals. High levels of TP in the blood can lead to poisoning the patient [3]. Because of this, it is crucial to have a method which can detect TP in a simple, rapid, and efficient way. Currently there are some methods for detecting TP, such as liquid chromatographymass spectrometry (LC-MS) [4], thin-layer chromatography (TLC) [5], high performance liquid chromatography (HPLC) [6], high performance capillary electrophoresis (HPCE) [7], and electrochemical methods $[8,9]$. Electrochemical measurements, which are continuous, simple, and efficient, are already widely used for detecting xanthine alkaloids. For instance, Zen and coworkers determined trace amounts of TP in tea and drug formulations using

\footnotetext{
* Corresponding authors at: College of Chemistry and Chemical Engineering, Yantai University, China

E-mail addresses: xmzhuang@iccas.ac.cn (X. Zhuang), dan1231dan@163.com (D. Chen), wangshengnan@i.shu.edu.cn (S. Wang), liuht-ytu@163.com (H. Liu), lxchen@yic.ac.cn (L. Chen).
}

a Nafion ${ }^{\circledR}$ /lead-ruthenium oxide pyrochlore chemically modified electrode [10]. The results of 15 successive repeated measurementregeneration cycles showed a relative standard deviation of $1.3 \%$ for $10 \mu \mathrm{M} \mathrm{TP}$, indicating that the electrode renewal gives a good reproducible surface.

Graphene is a material with excellent electron conductivity [11] because electrons can move freely in its planes due to the presence of $\pi$ trajectory. Because of its conductivity and wide potential window, using graphene in modified electrodes promotes electron transfer [12]; this leads to materials with excellent electrocatalytic properties [13]. Agglomeration, however, can occur in graphene during the liquid reduction process [14], which is required for graphene to be functionalized to maintain its inherent properties. Functionalized graphene can retain the excellent properties of graphene, while the functional groups may impart graphene with additional properties [15]. Because of their wide range of solubilities and the introduction of surface charge, ionic liquid-functionalized graphene (IL-graphene) sheets were prepared [16], and the materials showed good dispersibility and long-term stability in various solvents. In addition, IL-graphene based electrochemical sensors have been widely reported in the literature for detecting various types of compounds, such as nitrite [17], NADH [18], hydrogen peroxide [19], and glucose [20].

The deposition of metal or metallic oxide nanomaterial on graphene or graphene oxide (GO) can greatly increase the spac- 
ing of layers to improve the dispersibility of graphene and also add the characteristics of a metal composite material [21]. Manganese dioxide $\left(\mathrm{MnO}_{2}\right)$ nanomaterial is widely used in electrochemistry because of its superior conductivity, electrochemical performance, and relatively high potential [22]. $\mathrm{MnO}_{2}$ is often used together with carbon materials such as carbon nanotubes [23], graphene [24], and GO [25], which enhance $\mathrm{MnO}_{2}$ activity and stability; moreover, a synergistic effect on the electrochemical performance of the nanomaterials is also observed. Lee and coworkers reported a template-free and simple synthesis process for flexible reduced graphene oxide (RGO)/ $\mathrm{MnO}_{2}$ paper electrodes [26]. The electrochemical capacitors were fabricated with $\mathrm{RGO} / \mathrm{MnO}_{2}$ and had an areal capacitance of $897 \mathrm{mF} \mathrm{cm}{ }^{-2}$, an energy density of $11.5 \mu \mathrm{Wh} \mathrm{cm} \mathrm{cm}^{-2}$, and a capacitance retention of $84 \%$ over 3600 cycles. Despite these promising results, there are currently relatively few studies on $\mathrm{GO}$ and $\mathrm{MnO}_{2}$ nanocomposites for electrochemical biosensors $[27,28]$.

In this paper, we combined IL-graphene and $\mathrm{MnO}_{2}$ nanosheets to fabricate an electrode which could be used as effective sensor for TP electroanalysis. Combining the benefits of IL-graphene and $\mathrm{MnO}_{2}$ nanosheets for electrochemical sensing applications, a remarkable synergistic increase of the electrochemical performance was achieved. The electrochemical properties and the $\mathrm{pH}$ effect of the sensing platform were evaluated using electrochemical techniques. The results revealed that the $\mathrm{MnO}_{2}$ nanosheets/ILgraphene/GCE had excellent electrocatalytic activity toward TP oxidation. TP concentrations lower than micromolar could be detected with the prepared electrochemical sensor.

\section{Experimental}

\subsection{Chemicals and materials}

GO was purchased from Nanjing XFNano Materials Technology Company (Nanjing, China). TP, 1-methylimidazole, 2bromoethylamine hydrobromide, manganese chloride tetrahydrate, tetramethyl ammonium, and hydrogen peroxide were obtained from Sigma (Shanghai, China). $\mathrm{K}_{3} \mathrm{Fe}(\mathrm{CN})_{6}, \mathrm{~K}_{4} \mathrm{Fe}(\mathrm{CN})_{6}$, $\mathrm{KCl}$, and acetic acid were purchased from Sinopharm Chemical Reagent Co.,Ltd (Beijing, China). All reagents were analytical grade and used as received. Nanopure deionized and distilled water $\left(18.2 \mathrm{M} \Omega \mathrm{cm}^{-1}\right.$ ) was used in all of the experiments.

\subsection{Apparatus}

Cyclic voltammetry (CV) and differential pulse voltammetry (DPV) were performed on a CHI660D electrochemical system (Chenhua Instruments, Shanghai, China) equipped with a personal computer for data storage and processing. The measuring unit was a conventional three-electrode system, with a GCE as the working electrode, an $\mathrm{Ag} / \mathrm{AgCl} / \mathrm{KCl}$ (saturated) electrode as the reference, and a platinum wire as the counter electrode. Transmission electron microscopy (TEM, JEOL 2010F, $200 \mathrm{kV}$ ) was used to study the morphology and microstructure of $\mathrm{MnO}_{2}$ nanosheets. Scanning electron microscopy (SEM) was performed on an S-4800 electron microscope (Hitachi, Ltd., Japan). All of the experiments were conducted at room temperature.

\subsection{Preparation procedure}

IL-graphene was prepared according to Niu's method [29], while $\mathrm{MnO}_{2}$ nanosheets were prepared from manganese chloride and hydrogen peroxide [30]. Tetramethyl ammonium solution $(12 \mathrm{~mL}$, $1.0 \mathrm{M}$ in water) mixed with hydrogen peroxide $(2 \mathrm{~mL}, 30 \mathrm{wt} \%$ in $\mathrm{H}_{2} \mathrm{O}$ ) was added to the aqueous solution $(10 \mathrm{~mL})$ and contained $0.563 \mathrm{~g}$ manganese chloride tetrahydrate within $15 \mathrm{~s}$. The

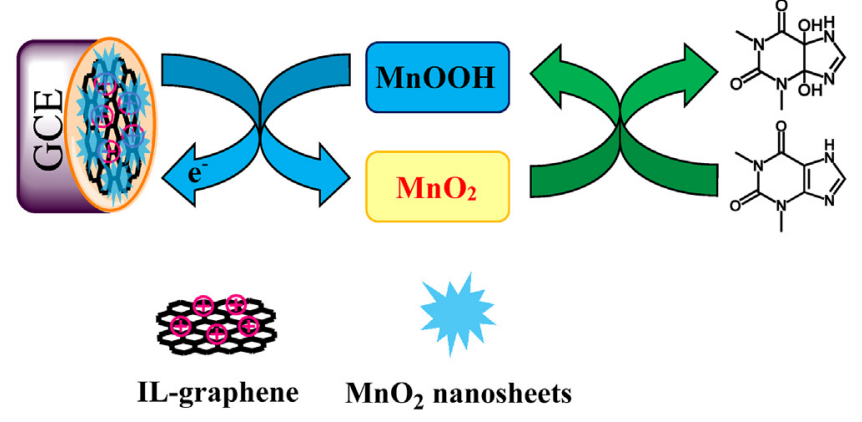

Scheme 1. Schematic illustration of the enhanced electrochemical detection strategy for TP based on $\mathrm{MnO}_{2}$ nanosheets/IL-graphene modified on the GCE.

resulting dark brown suspension liquid was stirred over night at room temperature. After washing with water three times, $\mathrm{MnO}_{2}$ nanosheets were obtained. To calculate the concentration of the $\mathrm{MnO}_{2}$ nanosheets in water, the absorption spectra at $380 \mathrm{~nm}$ were measured, and the concentration was calculated using the Beer-Lambert Law. The molar extinction coefficient was $9.6 \times 10^{3} \mathrm{M}^{-1} \mathrm{~cm}^{-1}[31]$.

The prepared IL-graphene $\left(1 \mathrm{mg} \mathrm{mL}^{-1}\right)$ was mixed with $\mathrm{MnO}_{2}$ nanosheets $(20.8 \mathrm{mM})$ in a $1: 1 \mathrm{vol}$ ratio. The solution was sonicated using ultrasound to obtain a homogeneous suspension. The composite was then washed with water three times, and $\mathrm{MnO}_{2}$ nanosheets/IL-graphene was obtained.

\subsection{Preparation of the modified electrode}

First, the GCE was polished to a mirror-like surface using $0.3 \mu \mathrm{m}$ and $0.05 \mu \mathrm{m} \gamma$-alumina slurries. The GCE was successively washed with ethanol and water in an ultrasonic bath and dried in air before use. $5 \mu \mathrm{L}$ of the $\mathrm{MnO}_{2}$ nanosheets/IL-graphene solution was dripped onto the surface of the GCE and slowly dried in ambient conditions to form the $\mathrm{MnO}_{2}$ nanosheets/IL-graphene-modified GCE $\left(\mathrm{MnO}_{2}\right.$ nanosheets/IL-graphene/GCE). This was then rinsed with water for the physical removal of the adsorbed species before use. The TP sensing strategy is illustrated in Scheme 1. CV was performed to characterize the different modified electrodes in $0.1 \mathrm{M}$ acetate buffer solutions or in a $1.0 \mathrm{mM} \mathrm{K}_{3}\left[\mathrm{Fe}(\mathrm{CN})_{6}\right] / \mathrm{K}_{4}\left[\mathrm{Fe}(\mathrm{CN})_{6}\right]$ $(1: 1)$ solution containing $0.1 \mathrm{M} \mathrm{KCl}$. Finally, the DPV signals were recorded in the range of $0.6 \mathrm{~V}$ to $1.6 \mathrm{~V}$ (increment: $0.005 \mathrm{~V}$; amplitude: $0.05 \mathrm{~V}$; pulse width: $0.1 \mathrm{~s}$; sampling width: 0.02; pulse period: $0.1 \mathrm{~s})$. In all of the electrochemical experiments, the soaking time before measurement was $2 \mathrm{~s}$.

\section{Results and discussion}

\subsection{Morphology and characterization}

The stability of $\mathrm{MnO}_{2}$ nanosheets is shown in Fig. S1A. After standing statically for $15 \mathrm{~h}$, the suspension solutions of $\mathrm{MnO}_{2}$ nanosheets were unchanged (Fig. S1A picture b), which indicated that the stability was excellent. The morphology of the $\mathrm{MnO}_{2}$ nanosheets was examined using TEM. Fig. S1B shows the typical TEM images of the $\mathrm{MnO}_{2}$ nanosheets, and the flexible flake-like morphology is evident. The surface morphologies of the different nanomaterials were investigated using SEM. Fig. 1 shows the typical image of IL-graphene ( $\mathrm{A}$ and $\mathrm{B}$ ), $\mathrm{MnO}_{2}$ nanosheets ( $\mathrm{C}$ and $\mathrm{D}$ ), and $\mathrm{MnO}_{2}$ nanosheets/IL-graphene ( $\mathrm{E}$ and $\mathrm{F}$ ). IL-graphene showed the characteristic crumpled and wrinkled structure (Fig. 1A and B), and the $\mathrm{MnO}_{2}$ nanosheets showed a lamellar and plate-like structures (Fig. 1C and D). After mixing the two materials together, the $\mathrm{MnO}_{2}$ nanosheets/IL-graphene nanocomposite presented a uni- 


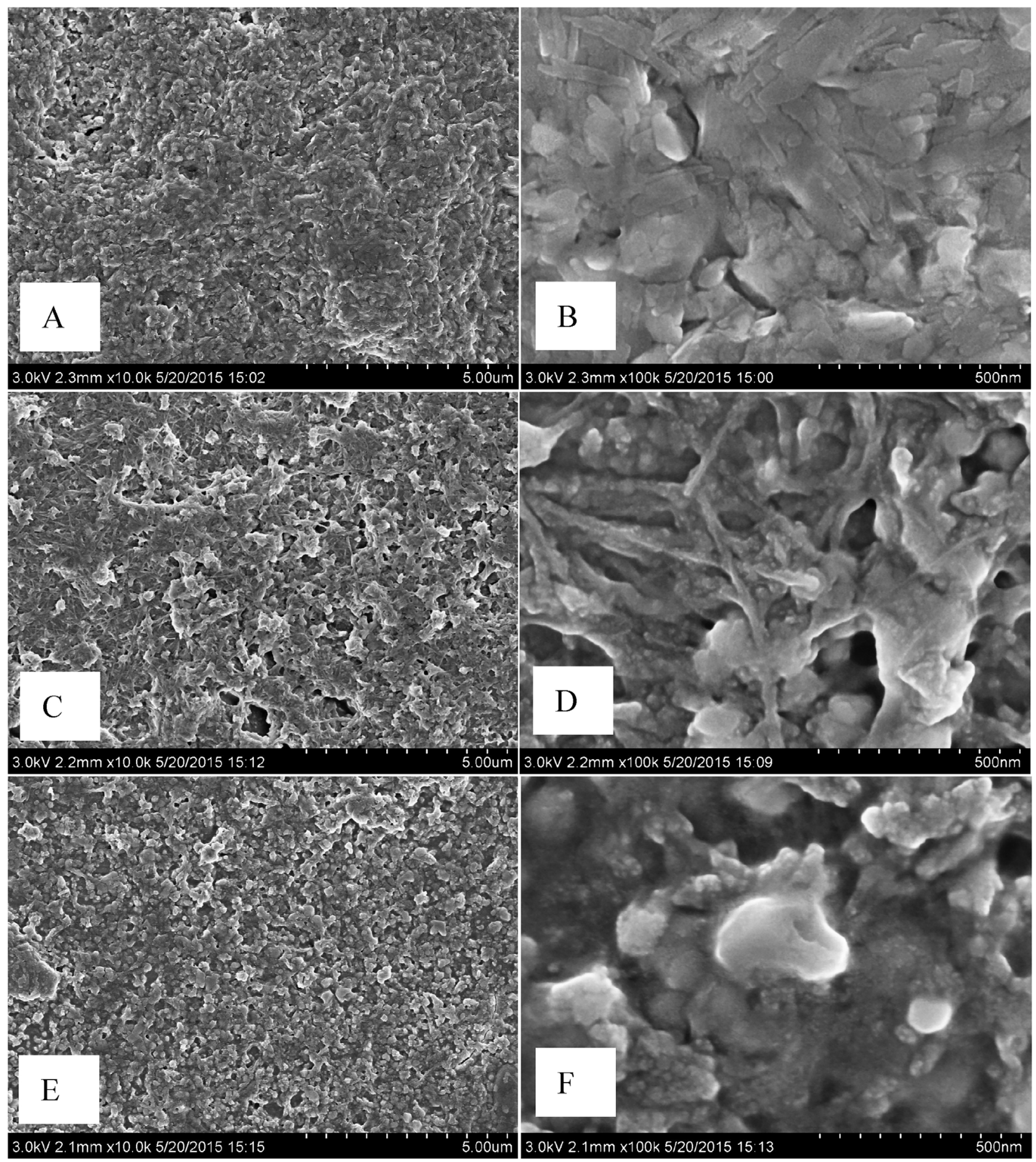

Fig. 1. SEM image of the IL-graphene ( $\mathrm{A}$ and $\mathrm{B}$ ), $\mathrm{MnO}_{2}$ nanosheets ( $\mathrm{C}$ and $\mathrm{D}$ ), and $\mathrm{MnO}_{2}$ nanosheets/IL-graphene (E and $\mathrm{F}$ ) with different magnifications

form distribution structure, indicating the successful attachment of the materials (Fig. 1E and F). The FT-IR spectrum of IL-graphene is shown in Fig. S2. The peaks at $2935 \mathrm{~cm}^{-1}$ and $2843 \mathrm{~cm}^{-1}$ (b and d) were ascribed to the $\mathrm{CH}_{3}(\mathrm{~N})$ and $\mathrm{CH}_{2}(\mathrm{~N})$ stretching vibrations, respectively. In particular, the stretching vibration of the $\mathrm{C}-\mathrm{N}$ bonds in the imidazole ring was clearly observed at $1637 \mathrm{~cm}^{-1}$ [32], further indicating the successful synthesis of the $\mathrm{MnO}_{2}$ nanosheets/IL-graphene. The $\mathrm{MnO}_{2}$ nanosheets/IL-graphene was further examined using X-ray photo-electron spectroscopy (XPS), and the results are shown in Fig. S3. The XPS spectrum (A) showed the presence of four elements: $\mathrm{C}, \mathrm{N}, \mathrm{O}$, and $\mathrm{Mn}$. The C1s spec- trum (B) showed three main types of carbon bonds: $C-C(284.6 \mathrm{eV})$, $\mathrm{C}-\mathrm{N}(285.9 \mathrm{eV})$, and epoxyl-carbon $(287.7 \mathrm{eV})$ [33]. In addition, the $\mathrm{N} 1 \mathrm{~s}$ band appeared at $401.7 \mathrm{eV}$ (Fig. 2C) with a lower bindingenergy shoulder at $397.9 \mathrm{eV}$, which clearly confirmed the presence of IL-graphene. The $M n 2 \mathrm{p}_{3 / 2}$ and $M n 2 \mathrm{p}_{1 / 2}$ spectrum (Fig. S3D) showed the presence of $\mathrm{MnO}_{2}$ [34]. Fig. S4 shows the Raman spectra of IL-graphene (curve a), the $\mathrm{MnO}_{2}$ nanosheets (curve b) and the $\mathrm{MnO}_{2}$ nanosheets/IL-graphene nanocomposite (curve c). The Raman spectrum of IL-graphene exhibited a slightly increased D/G intensity ratio relative to that of GO [33], and this may suggest a decrease in the average size of the $\mathrm{sp}^{2}$ domains in IL-graphene. 


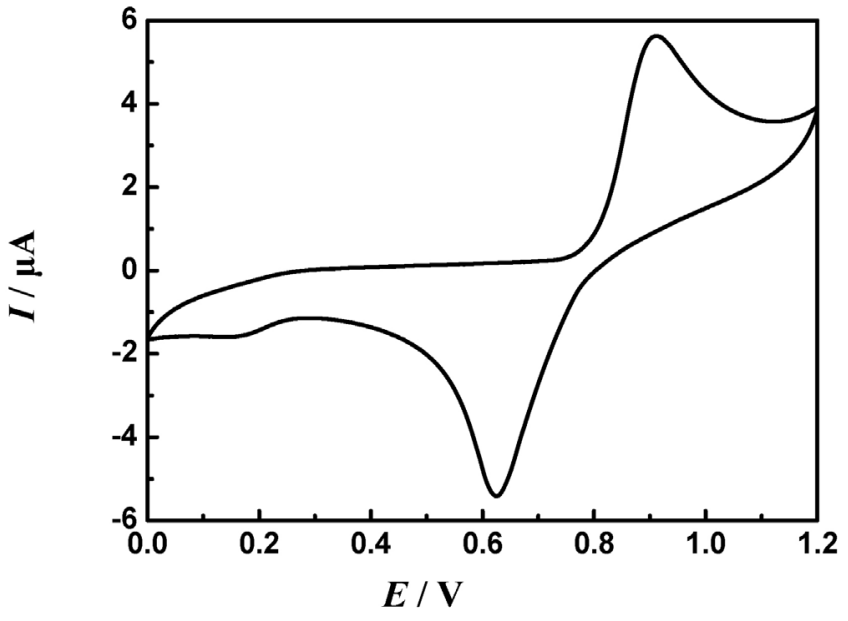

Fig. 2. $\mathrm{CV}$ response of the $\mathrm{MnO}_{2}$ nanosheets/IL-graphene/GCE in acetate buffer solutions ( $\mathrm{pH} \mathrm{5}$ ) at a scan rate of $20 \mathrm{mV} \mathrm{s}^{-1}$.

The Raman spectrum of the $\mathrm{MnO}_{2}$ nanosheets was not clearly observed, and the Raman spectrum of the $\mathrm{MnO}_{2}$ nanosheets/ILgraphene did not change compared to IL-graphene, which implied that the structure of IL-graphene did not change in the formation process. Elemental analysis (Table S1) showed that the imidazole cation was synthesized within the surface of GO and still existed after the formation of the nanocomposite.

\subsection{Electrochemical behavior of $\mathrm{MnO}_{2}$ nanosheets/IL-graphene/GCE}

The formation of the $\mathrm{MnO}_{2}$ nanosheets/IL-graphene/GCE composite was also verified by measuring the $\mathrm{CV}$ of the modified electrode in an acetate buffer solution ( $\mathrm{pH} 5$ ). As shown in Fig. 2, during the positive potential scan, an oxidation peak was observed at $0.91 \mathrm{~V}$, which can be attributed to the oxidation of $\mathrm{Mn}^{2+}$ to $\mathrm{Mn}^{4+}$ ions. A reduction peak was observed at $0.63 \mathrm{~V}$ during the cathodic scan, and this corresponded to the reduction of $\mathrm{Mn}^{4+}$ back to $\mathrm{Mn}^{2+}$ ions. According to the electrochemical-chemical-electrochemical (ECE) mechanism, the oxidation of $\mathrm{Mn}^{2+}$ in low acidic or neutral media is given by the equation [35]:

$\mathrm{Mn}^{2+}+2 \mathrm{H}_{2} \mathrm{O} \rightarrow \mathrm{MnO}_{2}+4 \mathrm{H}^{+}+2 \mathrm{e}^{-}$

During the fabrication process, investigation of barrier changes on the electrode surface was required. For this purpose, CV measurements of $1.0 \mathrm{mM}\left[\mathrm{Fe}(\mathrm{CN})_{6}\right]^{3-/ 4-}$ solutions were performed using different working electrodes; more specifically, a bare GCE, IL-graphene/GCE, $\mathrm{MnO}_{2}$ nanosheets/GCE, and $\mathrm{MnO}_{2}$ nanosheets/IL- graphene/GCE were investigated in an acetate buffer ( $\mathrm{pH}$ 6.5). As depicted in Fig. 3, the cyclic voltammogram of the bare GCE showed an oxidation peak current of $8.978 \mu \mathrm{A}$ and a reduction peak of $-9.050 \mu \mathrm{A}$ (curve a). When IL-graphene was immobilized on the same electrode, the oxidation and the reduction currents increased to 11.53 and $12.17 \mu \mathrm{A}$ respectively (curve b). This was because IL-graphene has an imidazole cation which has the ability to interact with the $\left[\mathrm{Fe}(\mathrm{CN})_{6}\right]^{3-/ 4-}$ ion via strong electrostatic interactions. On the $\mathrm{MnO}_{2}$ nanosheets/GCE (curve c), there were not well defined oxidation-reduction peaks, because the negative charge of the $\mathrm{MnO}_{2}$ nanosheets repelled the $\left[\mathrm{Fe}(\mathrm{CN})_{6}\right]$ $3-/ 4-$ anion. However, the oxidation and reduction currents of $9.126 \mu \mathrm{A}$ and $17.50 \mu \mathrm{A}$, respectively, were still observed with the $\mathrm{MnO}_{2}$ nanosheets/IL-graphene/GCE; this can be ascribed to the uniform distribution structure and consequently to the easier electron transfer at the electrode/solution interface. These data confirmed that the modified sensing interface was successfully developed.

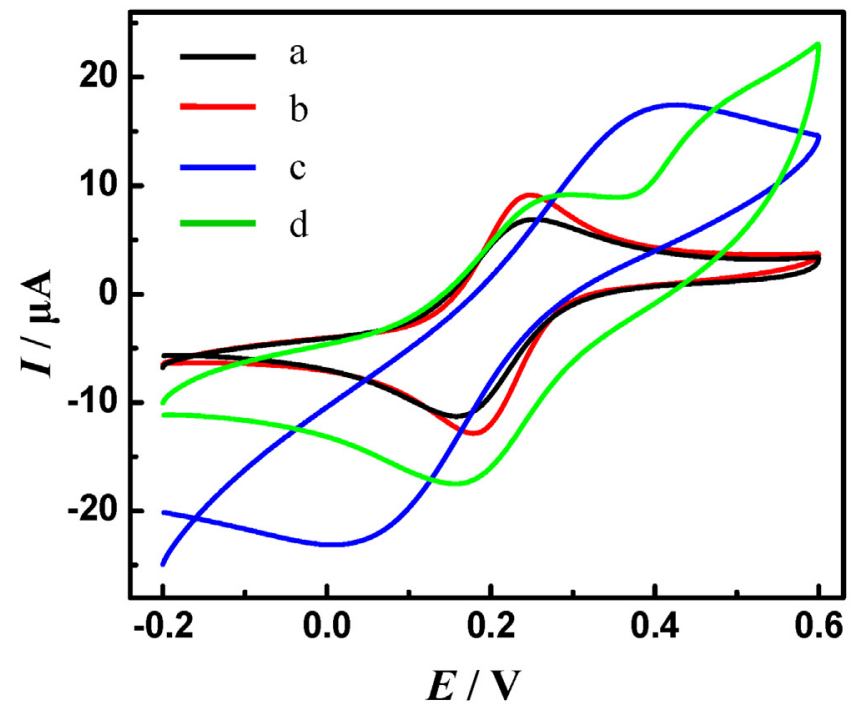

Fig. 3. $\mathrm{CVs}$ of $1.0 \mathrm{mM}\left[\mathrm{Fe}(\mathrm{CN})_{6}\right]^{3-/ 4-}$ in $0.1 \mathrm{M} \mathrm{KCl}$ recorded using: (a) the bare GCE, (b) the IL-graphene/GCE, (c) the $\mathrm{MnO}_{2}$ nanosheets/GCE, and (d) the $\mathrm{MnO}_{2}$ nanosheets/IL-graphene/GCE. The scan rate was $100 \mathrm{mV} \mathrm{s}^{-1}$.

\subsection{Effects of scan rate}

To investigate the reaction kinetics, the $\mathrm{MnO}_{2}$ nanosheets/ILgraphene/GCE was scanned using $\mathrm{CV}$ at various rates in a $0.1 \mathrm{M}$ acetic acid buffer solution $(\mathrm{pH}=5)$, and the results are shown in Fig. 4. As the scan rate increased, the redox peak current increased correspondingly. Moreover, both the cathodic and anodic peak currents increased with an increase in the scan rate from 0.01 to $0.1 \mathrm{~V} \mathrm{~s}^{-1}$. In addition, there was a linear correlation between the scan sweep rates $(v)$ and the anode $\left(E_{\mathrm{pa}}\right)$ and cathode $\left(E_{\mathrm{pc}}\right)$ peak potentials (see inset of Fig. 4). These results indicate that the electrochemical redox of $\mathrm{MnO}_{2}$ nanosheets/IL-graphene/GCE behaved as a typical adsorption-controlled process and as a surface-limited reaction. The surface concentration of the electroactive species, $\Gamma$, can be calculated from the slope of the plot of $\mathrm{I}_{\mathrm{pa}} \mathrm{Vs}$. scan rate using the following equation [36]:

$I=n^{2} \mathrm{~F}^{2} v A \Gamma / 4 R T$

where $A$ is the surface area, and $v$ is the sweep rate. The value of $\Gamma$ was calculated to be approximately $2.316 \times 10^{-10} \mathrm{~mol} \mathrm{~cm}^{-2}$.

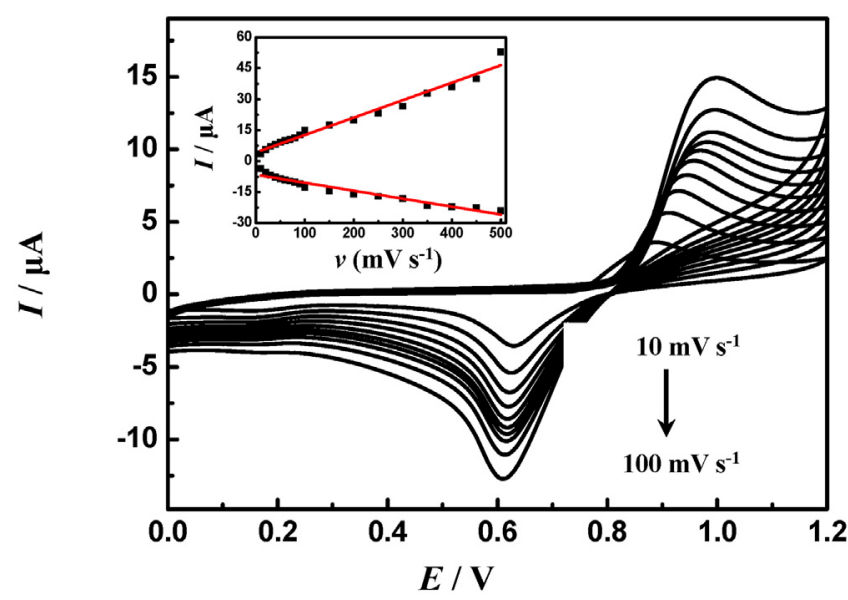

Fig. 4. $\mathrm{CV}$ responses of the $\mathrm{MnO}_{2}$ nanosheets/IL-graphene/GCE in a $0.1 \mathrm{M}$ acetate buffer solution ( $\mathrm{pH} \mathrm{5}$ ) at scan rates (from inner to outer) of: 10, 20, 30, 40, 50, 60, $70,80,90$, and $100 \mathrm{mV} \mathrm{s}^{-1}$. Inset shows the plot of peak current vs. scan rate. 


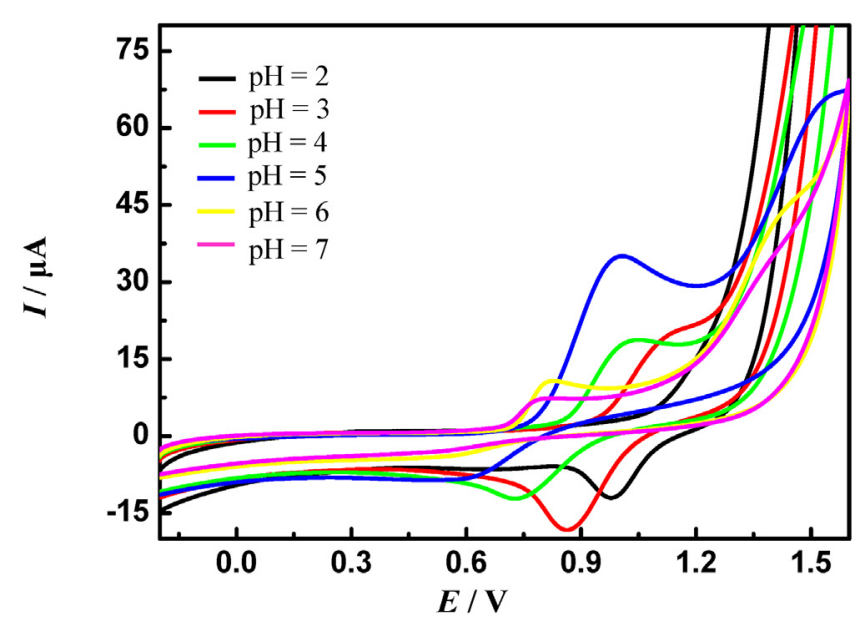

Fig. 5. $\mathrm{CVs}$ of the $\mathrm{MnO}_{2}$ nanosheets/IL-graphene/GCE in solutions with different $\mathrm{pH}$ values from 2 to 7 . The scan rate was $100 \mathrm{mV} \mathrm{s}^{-1}$.

\subsection{The effect of $p H$}

The electrochemical redox behavior of the $\mathrm{MnO}_{2}$ nanosheets/ILgraphene/GCE was investigated using $\mathrm{CV}$ in different buffering systems, with $\mathrm{pH}$ values varying from 2.0 to 7.0 , and the results are shown Fig. 5. The CV curves showed that $\mathrm{pH}$ has a significant effect on the electrochemical process. Because $\mathrm{MnOOH}$ is unstable in acidic media, the oxidation peak current (oxidation of $\mathrm{MnOOH}$ to $\mathrm{MnO}_{2}$ ) was largely reduced and nearly disappeared as seen in Fig. $5(\mathrm{pH}=2)$. At the same time, as the medium acidity decreased, the oxidation peak currents $\left(\mathrm{I}_{\mathrm{pa}}\right)$ increased. The maximum current was observed with a $\mathrm{pH}$ of 5 , and for higher $\mathrm{pH}$ values, the current decreased. Based on these results, a pH 5 buffer was chosen as the optimal $\mathrm{pH}$ value in this experiment.

\subsection{Amperometric sensing of TP}

To investigate the potential electrocatalytic activity of the $\mathrm{MnO}_{2}$ nanosheets/IL-graphene/GCE system for TP oxidation, DPV was performed. Electrochemical experiments were carried out both in the absence and in the presence of TP. As shown in Fig. 6, the electrochemical properties of GCE and the $\mathrm{MnO}_{2}$ nanosheets/GCE were compared with those of the modified electrode in a $0.1 \mathrm{M}$ acetic

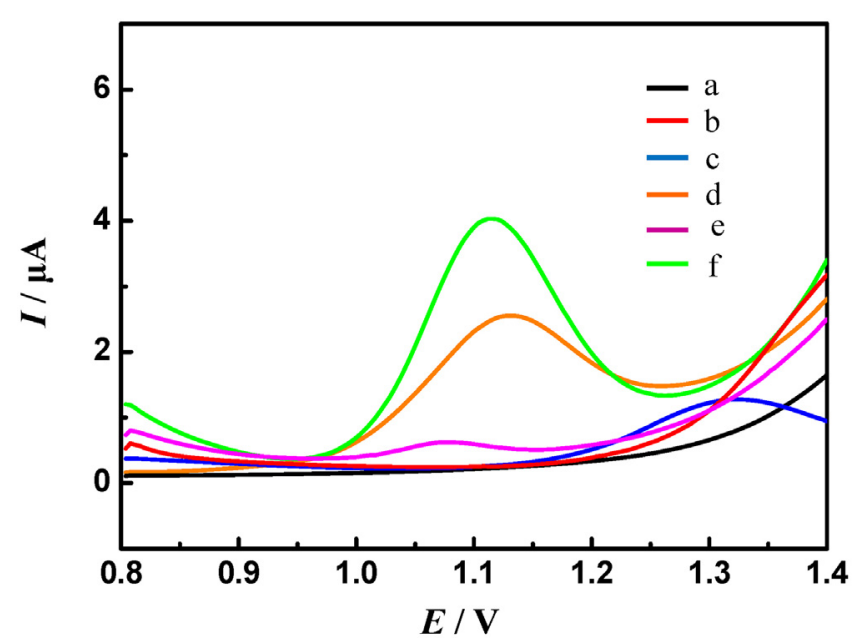

Fig. 6. DPVs recorded using the bare GCE ( $a$ and d), the $\mathrm{MnO}_{2}$ nanosheets/GCE (b and e), and the $\mathrm{MnO}_{2}$ nanosheets/IL-graphene/GCE (c and f) electrodes in the absence (a, b, and c) and presence ( $d, e$, and d) of $1 \mathrm{mM}$ TP in a $0.1 \mathrm{M}$ acetate buffer solution (pH 5). acid buffer $(\mathrm{pH}=5)$ in the absence and in presence of TP $(1 \mathrm{mM}$ concentration). With the bare GCE and the $\mathrm{MnO}_{2}$ nanosheets/GCE oxidation peaks of $1.581 \mu \mathrm{A}$ at $1.12 \mathrm{~V}$ and $0.3638 \mu \mathrm{A}$ at $1.08 \mathrm{~V}$ were detected with the $1 \mathrm{mM}$ TP solution, and the current increased to $3.143 \mu \mathrm{A}$ when the modified electrode was employed. No obvious signal was observed with either electrode in the absence of TP. The significant increase in the current was due to the improved electrocatalytic properties of the $\mathrm{MnO}_{2}$ nanosheets. Indeed, the superior catalytic properties of the $\mathrm{MnO}_{2}$ nanosheets were indicated by the reduced overpotential and the enhanced TP oxidation signal. These data showed that such material was suitable for the electron transfer between TP and the working electrode; moreover, it promoted the electrochemical regeneration of the TP electron exchange.

Based on the obtained results, a possible reaction mechanism for the TP oxidation with $\mathrm{MnO}_{2}$ nanosheets is shown below [36]:

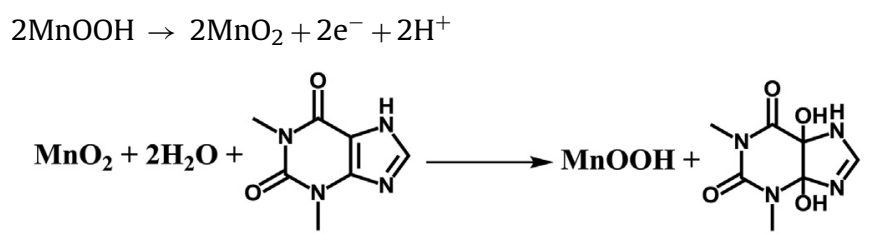

To optimize the electrocatalytic response for TP oxidation, the effect of pH was investigated. DPV was performed in acetic acid buffer at various pH with $5 \mathrm{mM}$ TP, as shown in Fig. 7. The oxidation between TP and $\mathrm{MnO}_{2}$ was significantly affected by $\mathrm{pH}$. The $\mathrm{MnO}_{2}$ nanosheets/IL-graphene/GCE showed electrocatalytic activity for $\mathrm{pH}$ between 3 and 8 . The maximum TP oxidation current was observed at $\mathrm{pH} 3$; the peak potential, however, was too high at this $\mathrm{pH}$. The second highest maximum current was obtained with $\mathrm{pH}$ 5. Therefore, $\mathrm{pH} 5$ was considered the optimum $\mathrm{pH}$ value for TP detection.

Additionally, the DPV response of the $\mathrm{MnO}_{2}$ nanosheets/ILgraphene/GCE electrode was measured with different concentrations of TP (Fig. 8). As shown in the figure, a well-defined peak was observed with the successive addition of $1 \mu \mathrm{M}$ TP, which demonstrated that the $\mathrm{MnO}_{2}$ nanosheets on the modified electrode were stable and efficient catalysts. Under the optimal conditions, the TP oxidation peak current $\left(\mathrm{I}_{\mathrm{pa}}\right)$ increased with concentration in the range from $1 \mu \mathrm{M}$ to $220 \mu \mathrm{M}$. The DPV current maximum shown in Fig. 8 was fitted using linear regression equations. Two fittings were performed depending on the TP concentration range: one for TP content between 1 and $10 \mu \mathrm{M}$, and one for TP content between 10 and $220 \mu \mathrm{M}$. According to this, the detection resolution limit was $0.1 \mu \mathrm{M}(\mathrm{S} / \mathrm{N}=3)$. To further confirm the advantages of the $\mathrm{MnO}_{2}$ nanosheets/IL-graphene/GCE for TP determination, Table S2 shows the comparison of this method was compared with other electrochemical methods and illustrates that $\mathrm{MnO}_{2}$ nanosheets/ILgraphene/GCE had excellent sensitivity and a wide linear range.

To evaluate the potential effect of foreign species on the determination of $50 \mu \mathrm{M}$ TP, a systematic study was carried out under the above optimized conditions. The peak currents of TP in the absence and presence of foreign species were measured using DPV. The results are listed in Table S3. It was found that 10-fold concentrations of $\mathrm{Fe}^{3+}, \mathrm{Ba}^{2+}, \mathrm{Al}^{3+}, \mathrm{Ni}^{2+}, \mathrm{Cu}^{2+}, \mathrm{CO}_{3}{ }^{2-}, \mathrm{PO}_{4}{ }^{3-}$, and $\mathrm{NO}_{3}{ }^{-} ; 2$-fold concentrations of phenol, hydroquinone, catechol, resorcinol, guanine, and caffeine did not interfere with the oxidation signal of TP (signal change below 5\%).

\subsection{Application of the probe}

The use of the proposed method in real sample analysis was also investigated using direct analysis of TP in a commercially available drug tablet ( $25.0 \mathrm{mg}$ per tablet). The effect of TP concentration was investigated using DPV with 5 repeated responses. The samples were spiked with a specified concentration of TP, and using the 

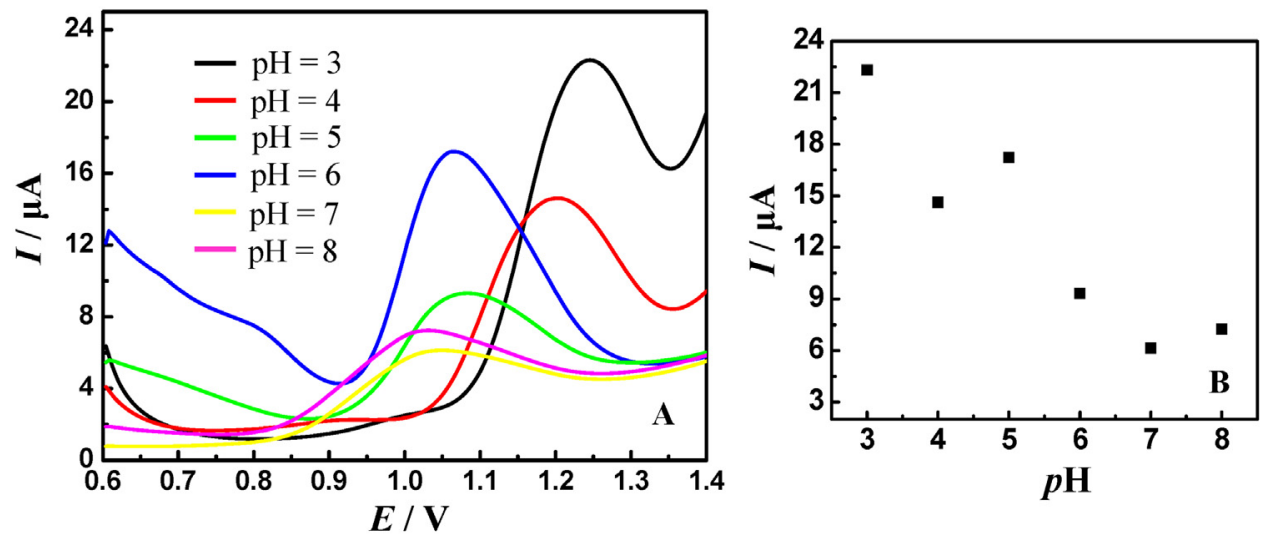

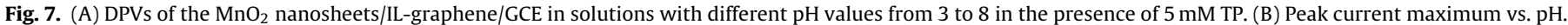
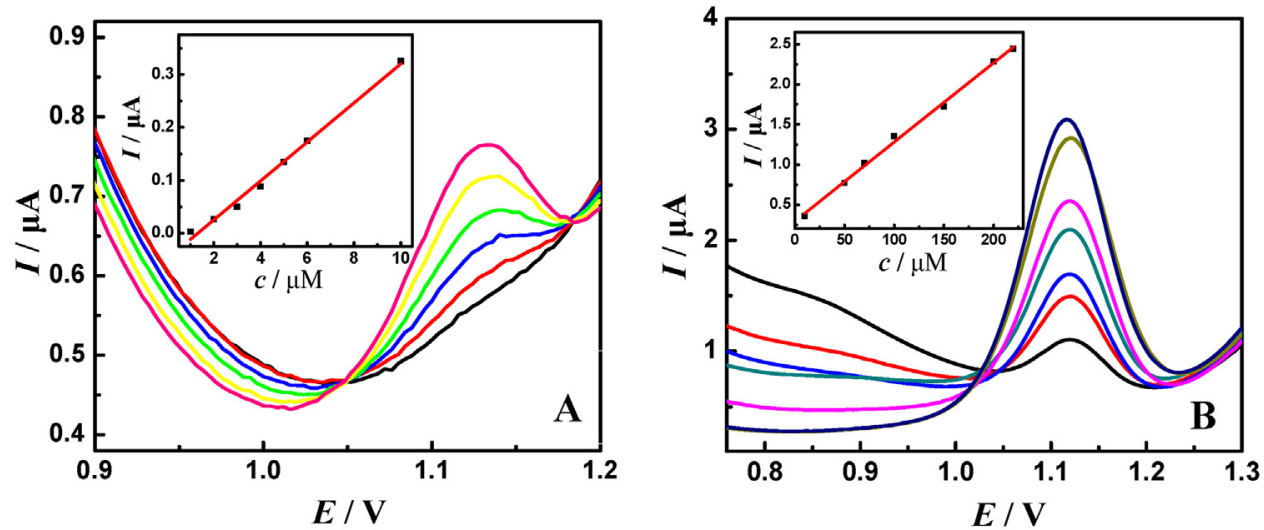

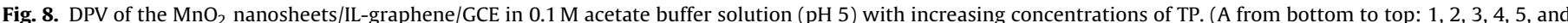
$6 \mu \mathrm{M}$ and B from bottom to top: $10,50,70,100,150,200$, and $220 \mu \mathrm{M}$.).

Table 1

Method recoveries for TP determination in a commercially available drug (25.0 mg per tablet, $\left.\operatorname{Mr}_{\mathrm{TP}}=180.16, n=5\right)$.

\begin{tabular}{|c|c|c|c|c|c|}
\hline Sample ( $\mu \mathrm{M})$ & Found $(\mu \mathrm{M})$ & Spiked $(\mu \mathrm{M})$ & Total Found $(\mu \mathrm{M})$ & Recovery (\%) & RSD (\%) \\
\hline 5 & 5.04 & 10 & 14.96 & 99.7 & 1.2 \\
\hline 10 & 9.98 & 10 & 20.05 & 100.4 & 1.6 \\
\hline 50 & 50.2 & 50 & 100.6 & 100.8 & 2.1 \\
\hline 100 & 99.1 & 50 & 149.0 & 99.0 & 2.9 \\
\hline
\end{tabular}

standard addition method, TP concentration measurements were made in the recovery rate of the spiked samples. The results are listed in Table 1 and demonstrate that the $\mathrm{MnO}_{2}$ nanosheets/ILgraphene/GCE might be a promising system for detecting TP in real samples.

\section{Conclusions}

In summary, a novel electrochemical system was proposed based on a new nanocomposite made of $\mathrm{MnO}_{2}$ nanosheets and IL-graphene as modifiers on the GCE. The $\mathrm{MnO}_{2}$ nanosheets/ILgraphene/GCE exhibited excellent redox response and effective electrocatalytic activity towards TP oxidation. The electrocatalytic activity of the $\mathrm{MnO}_{2}$ nanosheets led to greatly improved electrochemical sensitivity in TP detection using the DPV technique. The detection resolution limit of the proposed sensor was $0.1 \mu \mathrm{M}$ in a concentration range from $1 \mu \mathrm{M}$ to $220 \mu \mathrm{M}$. Finally, the $\mathrm{MnO}_{2}$ nanosheets/IL-graphene/GCE was also used to detect TP content in drug samples with satisfactory results. This study offers a new approach for TP sensing and also provides new insight into the application of $\mathrm{MnO}_{2}$ nanosheets in electrochemical sensors.

\section{Acknowledgments}

This work was financially supported by the National Natural Science Foundation of China (21405132, 21575159) and the Young Scholars Fund of Yantai University (Grant HY13B21).

\section{Appendix A. Supplementary data}

Supplementary data associated with this article can be found, in the online version, at http://dx.doi.org/10.1016/j.snb.2017.05.049.

\section{References}

[1] L.L. Somerville, Theophylline revisited, Allergy Asthma Proc. 22 (2001) 347-351.

[2] T.T. Hansel, R.C. Tennant, A.J. Tan, L.A. Higgins, H. Neighbour, E.M. Erin, P.J. Barnes, Theophylline Mechanism of action and use in asthma and chronic obstructive pulmonary disease, Drug Today 40 (2004) 55-69.

[3] P.J. Barnes, Theophylline, Am. J. Respir. Crit. Care Med. 188 (2013) 901-906.

[4] S. Riahi, M.F. Mousavi, S.Z. Bathaie, M. Shamsipur, A novel potentiometric sensor for selective determination of theophylline: theoretical and practical investigations, Anal. Chim. Acta 548 (2005) 192-198.

[5] P.U. Sanganalmath, K.M. Sujatha, S.M. Bhargavi, V.G. Nayak, B.M. Mohan, Simple, accurate and rapid HPTLC method for analysis of theophylline in 
post-mortem blood and Validation of the method, JPC- J. Planar Chromatogr. 22 (2009) 29-33.

[6] K. Ma, H.F. Wang, M. Zhao, J.J. Xing, Purity determination and uncertainty evaluation of theophylline by mass balance method, high performance liquid chromatography and differential scanning calorimetry, Anal. Chim. Acta 650 (2009) 227-233.

[7] M.J. Li, J.Y. Zhou, X. Gu, Y. Wang, X.J. Huang, C. Yan, Quantitative capillary electrophoresis and its application in analysis of alkaloids in tea coffee, coca cola, and theophylline tablets, J. Sep. Sci. 32 (2009) 267-274.

[8] S. Guney, F.C. Cebeci, Selective electrochemical sensor for theophylline based on an electrode modified with imprinted sol-gel film immobilized on carbon nanoparticle layer, Sensor Actuat. B-Chem. 208 (2015) 307-314.

[9] S. Kesavan, S.A. John, Fabrication of aminotriazole grafted gold nanoparticles films on glassy carbon electrode and its application towards the simultaneous determination of theophylline and uric acid, Sensor Actuat. B-Chem. 205 (2014) 352-362

[10] J.M. Zen, T.Y. Yu, Y. Shih, Determination of theophylline in tea and drug formulation using a Nafion ${ }^{\circledR} /$ lead-ruthenium oxide pyrochlore chemically modified electrode, Talanta 50 (1999) 635-640.

[11] D.R. Dreyer, S. Park, C.W. Bielawski, R.S. Ruoff, The chemistry of graphene oxide, Chem. Soc. Rev, 39 (2010) 228-240.

[12] Y.X. Liu, X.C. Dong, P. Chen, Biological and chemical sensors based on graphene materials, Chem. Soc. Rev. 41 (2012) 2283-2307.

[13] P.G. Hu, K. Liu, C.P. Deming, S.W. Chen, Multifunctional graphene-based nanostructures for efficient electrocatalytic reduction of oxygen, J. Chem. Technol. Biotechnol. 90 (2015) 2132-2151.

[14] C.I. Wang, A.P. Periasamy, H.T. Chang, Photoluminescent C-dots@RGO probe for sensitive and selective detection of acetylcholine, Anal. Chem. 85 (2010) 3263-3270.

[15] P. Bhunia, E. Hwang, M. Min, J. Lee, S. Seo, S. Some, H. Lee, A non-volatile memory device consisting of graphene oxide covalently functionalized with ionic liquid, Chem. Commun. 48 (2012) 913-915.

[16] N. Zhou, J.H. Li, H. Chen, C.Y. Liao, L.X. Chen, A functional graphene oxide-ionic liquid composites-gold nanoparticle sensing platform for ultrasensitive electrochemical detection of Hg2+, Analyst 138 (2013) 1091-1097.

[17] W. Sun, D.D. Wang, R.F. Gao, K. Jiao, Direct electrochemistry and electrocatalysis of hemoglobin in sodium alginate film on a BMIMPF$_{6}$ modified carbon paste electrode, Electrochem. Commun. 9 (2007) 1159-1164.

[18] C.S. Shan, H.F. Yang, D.X. Han, O.X. Zhang, A. Ivaska, L. Niu, Electrochemical determination of NADH and ethanol based on ionic liquid-functionalized grapheme, Biosens. Bioelectron. 25 (2010) 1504-1508.

[19] Q. Wang, Y.B. Yun, Nonenzymatic sensor for hydrogen peroxide based on the electrodeposition of silver nanoparticles on poly(ionic liquid)-stabilized graphene sheets, Microchim. Acta 180 (2013) 261-268.

[20] Y.Y. Jiang, Q.X. Zhang, H.F. Li, L. Niu, Glucose oxidase and graphene bionanocomposite bridged by ionic liquid unit for glucose biosensing application, Sensor Actuat. B-Chem. 161 (2012) 728-733.

[21] M. Khan, M.N. Tahir, S.F. Adil, H.U. Khan, M.R.H. Siddiqui, A.A. Al-warthan, W. Tremel, Graphene based metal and metal oxide nanocomposites: synthesis, properties and their applications, J. Mater. Chem. A 3 (2015) 18753-18808.

[22] S. Schmachtel, M. Toiminen, K. Kontturi, O. Forsen, M.H. Barker, New oxygen evolution anodes for metal electrowinning: $\mathrm{mnO}_{2}$ composite electrodes, $\mathrm{J}$. Appl. Electrochem. 39 (2009) 1835-1848.

[23] H.J. Huang, W.Y. Zhang, Y.S. Fu, X. Wang, Controlled growth of nanostructured $\mathrm{MnO}_{2}$ on carbon nanotubes for high-performance electrochemical capacitors, Electrochim. Acta 152 (2015) 480-488.

[24] M.R. Mahmoudian, Y. Alias, W.J. Basirun, P.M. Woi, M. Sookhakian, Facile preparation of $\mathrm{MnO}_{2}$ nanotubes/reduced graphene oxide nanocomposite for electrochemical sensing of hydrogen peroxide, Sensor Actuat. B-Chem. 201 (2014) 526-534.

[25] T. Gan, J.Y. Sun, K.J. Huang, L. Song, Y.M. Li, A graphene oxide-mesoporous $\mathrm{MnO}_{2}$ nanocomposite modified glassy carbon electrode as a novel and efficient voltammetric sensor for simultaneous determination of hydroquinone and catechol, Sensor Actuat. B-Chem. 177 (2013) 412-418.

[26] A. Sumboja, C.Y. Foo, X. Wang, P.S. Lee, Large areal mass, flexible and free-standing reduced graphene oxide/manganese dioxide paper for asymmetric supercapacitor device, Adv. Mater. 25 (2013) 2809-2815.

[27] S. Dong, J. Xi, Y. Wu, H. Liu, C. Fu, H. Liu, F. Xiao, High loading $\mathrm{MnO}_{2}$ nanowires on graphene paper: facile electrochemical synthesis and use as flexible electrode for tracking hydrogen peroxide secretion in live cells, Anal. Chim. Acta 853 (2015) 200-206.
[28] T. Gan, J. Sun, K. Huang, L. Song, Y. Li, A graphene oxide-mesoporous $\mathrm{MnO}_{2}$ nanocomposite modified glassy carbon electrode as a novel and efficient voltammetric sensor for simultaneous determination of hydroquinone and catechol, Sensor Actuat. B-Chem. 177 (2013) 412-418.

[29] C. Shan, H. Yang, D. Han, Q. Zhang, A. Ivaskac, L. Niu, Electrochemical determination of NADH and ethanol based on ionic liquid-functionalized graphene, Biosens. Bioelectron. 25 (2010) 1504-1508.

[30] W. Zhai, C. Wang, P. Yu, Y. Wang, L. Mao, Single-layer $\mathrm{MnO}_{2}$ nanosheets suppressed fluorescence of 7-hydroxycoumarin: mechanistic study and application for sensitive sensing of ascorbic acid in vivo, Anal. Chem. 86 (2014) 12206-112213.

[31] K. Kai, Y. Yoshida, H. Kageyama, G. Saito, T. Ishigaki, Y. Furukawa, J. Kawamata, Room-temperature synthesis of manganese oxide nanosheets, J. Am. Chem. Soc. 130 (2008) 15938-15943.

[32] J. Lian, X. Duan, J. Ma, P. Peng, T. Kim, W. Zheng, Hematite $\left(\alpha-\mathrm{Fe}_{2} \mathrm{O}_{3}\right)$ with various morphologies: ionic liquid-assisted synthesis, formation mechanism, and properties, ACS Nano 3 (2009) 3749.

[33] S. Guo, D. Wen, Y. Zhai, S. Dong, E. Wang, Ionic liquid-graphene hybrid nanosheets as an enhanced material for electrochemical determination of trinitrotoluene, Biosens. Bioelectron. 26 (2011) 3475-3481.

[34] E. Beyreuther, S. Grafström, L.M. Eng, C. Thiele, K. Dörr, XPS investigation of Mn valence in lanthanum manganite thin films under variation of oxygen content, Phys. Rev. B 73 (2006) 155425.

[35] E. Laviron, Adsorption, autoinhibition and autocatalysis in polarography and in linear potential sweep voltammetry, J. Electroanal. Chem. 52 (1974) 355-393.

[36] S. MansouriMajd, H. Teymourian, A. Salimia, R. Hallaj, Fabrication of electrochemical theophylline sensor based onmanganese oxide nanoparticles/ionic liquid/chitosan nanocomposite modified glassy carbon electrode, Electrochim. Acta 08 (2013) 707-716.

\section{Biographies}

Xuming Zhuang received his $\mathrm{PhD}$ in analytical chemistry from the Department of Chemistry of Shandong University, Jinan, in 2013. In the same year, he joined in College of Chemistry and Chemical Engineering, Yantai University, as a lecturer. His current research interest focuses on preparation of novel electrochemical biosensors and applications to in vivo analysis.

Dandan Chen received her BS degree from College of Chemistry and Chemical Engineering, Yantai University, in 2015. She is studying for her master degree in College of Chemistry and Chemical Engineering, Yantai University. Her current research interest is the electrochemical biosensor and detection of small biomolecules.

Shengnan Wang received her BS degree from College of Chemistry and Chemical Engineering, Yantai University, in 2015. She is studying for her master degree in Department of Chemistry, College of Science, Shanghai University. Her current research interest is the proton exchange membrane (PEM), which is the core part of the PEMFCs and improving its comprehensive performances.

Huitao Liu received her PhD degree in analytical chemistry from Lanzhou University, Lanzhou, in 2000. After a year of postdoctoral experience at the Department of Chemistry, National Sun Yat-sen University, Kaohsiung, Taiwan, she joined as a professor, College of Chemistry and Chemical Engineering, Yantai University. Her research interests include the development of food and medicine analysis methods using capillary electrophoresis and high performance liquid chromatography; preparation of novel functionalized nanomaterials and their application in analytical chemistry.

Lingxin Chen has been a professor at Yantai Institute of Coastal Zone Research, Chinese Academy of Sciences, since 2009. He obtained his Ph.D. in analytical chemistry at Dalian Institute of Chemical Physics, Chinese Academy of Sciences, in 2003. During 2004-2009, he worked at Department of Chemistry, Tsinghua University, and Department of Applied Chemistry, Hanyang University, respectively. His research interests include the studies of novel properties of materials such as functionalized nanoparticles \& functional probe molecules for developing nanoscale biochemical analysis methods and molecular imprinting-based sample pretreatment technology. 